\title{
Organisation of telephone services and patients' access to doctors by telephone in general practice
}

\author{
Lesley Hallam
}

\begin{abstract}
Objectives-To assess how accessible general practitioners are to patients by telephone and to examine the relations between organisation, number of lines, and number of patient-doctor calls.

Design-Postal survey of a random sample of general practitioners stratified by rural and urban practice areas, with differential sampling fractions.

Setting-General practices in England and Wales.

Subjects-2000 general practitioners, of whom $1459(74 \%)$ responded.
\end{abstract}

Main outcome measures-Number of calls received by general practitioner a day, time reserved for patients' calls, and communication of availability of telephone contact.

Results -1421 general practitioners said that they accepted non-emergency calls from patients during the day and 285 reported reserving specific times of the day for this purpose. 848 estimated that they received four or fewer patient calls a day. The number of calls was significantly related to reserving time for calls $(p<0.001)$, informing patients that the doctor was accessible by telephone $(p<0.00001)$, and the number of periods when calls were accepted $(p<0.00001)$. On average there were 3659 patients per incoming line; the number of patients per incoming line rose significantly as practice size increased $(\mathbf{p}<0.00001)$.

Conclusions - The apparent willingness of general practitioners to accept calls was not reflected in the number of calls received. Reserving time, increasing periods of availability, and publicising telephone access increased the number of doctor-patient telephone contacts. Line congestion may be a problem, and impartial advice and guidance on telephone organisation and line requirements would be helpful.

\section{Introduction}

Information on use of the telephone in general practice is limited and telephone use is rarely discussed in British medical journals. ${ }^{1}$ What little is known suggests that doctor-patient telephone contacts are less common in Britain than in other developed countries. ${ }^{2}$ The United States and Scandinavia, in particular, make substantial use of the telephone in providing primary care and have published many papers describing its role and assessing its use and value. ${ }^{3}$

There are virtually no British data on telephone contacts during surgery hours, ${ }^{4}$ though some studies on out of hours contacts have been reported. ${ }^{5-8}$ There is anecdotal evidence that general practitioners discourage direct patient contact, often through their receptionists. ${ }^{59-11}$ Conversely, it has been suggested that as patients know a doctor will see them in surgery or at home they may not wish to seek telephone advice.
In fact a high proportion of patients have never attempted to telephone their doctor and a substantial minority believe it is not permissible. ${ }^{11}$ Despite this a recent survey showed that $84 \%$ of patients thought they should be able to do so. ${ }^{12}$ The increased emphasis now placed on responding to patients' wishes, coupled with increasing workload for general practitioners, make it appropriate to examine and reassess the provision of telephone services in general practice. Though the attitude of individual practitioners to direct telephone contact with patients may be the prime determinant of the number of patients' calls they receive, the number of telephone lines and the manner in which telephone access is organised may also be a factor.

This paper deals specifically with telephone equipment, the organisation of telephone services, the accessibility of general practitioners by telephone, and the volume of patient-doctor telephone calls. The survey on which it is based is the first stage of a wider study of telephone access to general practitioners and practice nurses. The survey aimed at providing a descriptive overview of current telephone facilities and access to general practitioners and to test hypotheses about the relation between numbers of patient-doctor calls and practice area, availability of general practitioners, and information given to patients.

\section{Methods}

The study population consisted of all unrestricted principals in general practice working in England and Wales. Those in Scotland were excluded. The sampling frame used was the October 1988 quarterly file of the BMA's doctor index. A sample of 2000 doctors was necessary because later stages of the project entailed interviewing doctors with extensive telephone contacts with patients and organised telephone advice sessions. Such doctors are unusual enough to feature in headlines in the popular medical press, ${ }^{1314}$ and a small sample would be unlikely to identify many. Such doctors might also be concentrated in rural areas, where greater distances and poorer public transport could make telephone use more attractive. The doctor index identifies general practitioners receiving rural practice payments, and, though crude, this permitted stratification into rural and non-rural populations. A disproportionately larger fraction of rural doctors were randomly sampled: 780 of the 7713 rural principals on the file compared with 1220 of the 18796 other principals, again with the aim of identifying more potential interviewees. Samples were computer generated.

A postal questionnaire was designed specifically for the survey. In the absence of any previous studies on the subject, extensive development work was necessary, which included personal interviews and prepilot tests. A full postal pilot study was mounted on
Lesley Hallam, research

coordinator

$B M \mathcal{F}$ 1991;302:629-32 
TABLE I-Distribution of patient to line ratios in general practices before and after adjusting for lines not available to patients

No $(\%)$ of general practitioners

\begin{tabular}{lcc}
\cline { 2 - 3 } $\begin{array}{l}\text { No of } \\
\text { patients/line }\end{array}$ & $\begin{array}{c}\text { All lines } \\
(\mathrm{n}=740)\end{array}$ & $\begin{array}{c}\text { Available } \\
\text { lines } \\
(\mathrm{n}=735) \dagger\end{array}$ \\
\hline$<2000$ & $177(24)$ & $90(12)$ \\
-2999 & $314(42)$ & $202(27)$ \\
-3999 & $167(23)$ & $188(26)$ \\
-4999 & $46(6)$ & $125(17)$ \\
-5999 & $21(3)$ & $66(9)$ \\
$\geqslant 6000$ & $15(2)$ & $64(9)$
\end{tabular}

* Mean (SD) number of patients/ line $=2742$ (1319)

+ Mean $(\mathrm{SD})$ number of patients

line $=3659$ (1846).
200 general practitioners randomly selected from the quarterly file of the doctor index by the methods used for the full sample. The main postal survey took place between September and November 1989. Up to three approaches were made to maximise the response. On the third approach, doctors were urged to complete the full questionnaire but were also sent an alternative, abbreviated version.

Except for analyses dealing with differences between rural and non-rural practitioners, data were weighted by factors of 0.704 for the rural sample and 1.207 for the non-rural sample to correct for the differential sampling fractions used. Data were analysed with the statistical package for the social sciences (SPSS-X). As sampling was random, the $\chi^{2}$ test was considered appropriate. Only results that achieved a probability of $p \leqslant 0.01$ were treated as significant. Many analyses are based on respondents to the full questionnaire only. When respondents who returned the abbreviated questionnaire are included in analyses this is stated.

\section{Results}

\section{RESPONSE RATES}

Of the 2000 general practitioners randomly selected 20 had died, retired, or left their practice without a successor. This reduced the sample to 1980 . (Where successors had been appointed, they were included in the sample as replacements.) Of the rural sample, 563 $(73 \%)$ returned the full questionnaire and $38(5 \%)$ returned the abbreviated version; $790(65 \%)$ and $68(6 \%)$ of the non-rural sample responded to the full and abbreviated questionnaires respectively. Thus full data were available for $1353(68 \%)$ of the sample and more limited data for a further $106(5 \%)$. The characteristics of respondents were compared with published national statistics on age, sex, premises, and practice size. ${ }^{15} 16$ No differences were found for age, sex, and premises, but there was a bias toward those in larger practices. Sixty two per cent of respondents were in practices of four or more partners compared with $55 \%$ nationally. There were no apparent differences between respondents returning full and abbreviated questionnaires. Response rates varied considerably across the country. The lowest response came from general practitioners in Mersey region (59\%) and the highest from Oxford region $(87 \%)$.

\section{ORGANISATION AND EQUIPMENT}

Answering incoming calls was predominantly a shared responsibility among reception staff. Four hundred and five respondents $(30 \%)$ said that an organised rota of receptionists answered calls, whereas $459(34 \%)$ left it to any receptionist who was free at the time. A further 61 (5\%) left it to anyone available, including non-reception staff. In 357 cases $(26 \%)$ one person answered all calls, either a switchboard operator or designated receptionist. Though 342 respondents $(25 \%)$ said that their patients were asked to dial separate numbers for some services, notably appointments, home visits, or repeat prescriptions, only $44(3 \%)$ said that different members of staff answered different lines. Nearly three quarters of respondents $(969 ; 72 \%)$ asked patients to limit their telephone requests for some services-for example, home visits and repeat prescriptions-to particular times of day.

For a subgroup of 740 general practitioners it was possible to calculate the number of registered patients per practice line. (Respondents with branch surgeries or lines shared with other practices were excluded.) The mean number of patients per practice lirre was 2742 , and wide variations in line provision were apparent. However, $810(60 \%)$ of those who completed the full questionnaire said that one or more of the practice lines were exdirectory or otherwise unavailable for incoming patient calls. A second patient to line ratio that excluded these lines was calculated for 735 respondents. The mean number of patients per available line rose to 3659 , and the extent of variation increased (table I).

Both ratios were significantly related to practice size $(\mathrm{p}<0.00001)$. Though $56(80 \%)$ of the 70 singlehanded doctors in the subgroup had only one line, their list rarely exceeded 3000 and thus nearly all had ratios below 3000:1. Few had additional lines not available to patients. As practice size rose so did the number of patients per practice line and the likelihood that one or more of those lines was unavailable to patients. The effect was further to increase the number of patients per available line (table II). Patient to line ratios were not related to the practice organisational feature most likely to affect the volume of incoming calls - that is, the use of appointment systems. Similar proportions of respondents with ratios below 3000:1 and ratios above $5000: 1$ had all appointment systems $(76 \%$ and $77 \%$ respectively).

TABLE II - Relation between number of patients per available line and number of partners in practice ${ }^{\star}$

\begin{tabular}{lcccccc}
\hline & \multicolumn{5}{c}{ No $(\%)$ of respondents in practices with following } \\
No of partners:
\end{tabular}

$\chi^{2}=201 \cdot 48, \mathrm{df}=25, \mathrm{p}<0 \cdot 00001$

$\star$ Numbers in rows and columns do not correspond owing to computer weighting.

General practitioners did seem to recognise where potential problems existed. As the patient to available line ratio increased so did the proportion of general practitioners feeling a need for additional lines, rising from $29 \%$ of the 292 with fewer than 3000 patients per line to $57 \%$ of the 130 with 5000 or more $(\mathrm{p}<0.00001)$. Overall, $550(41 \%)$ respondents said that they would like more lines. Other improvements that between $20 \%$ and $25 \%$ of respondents would like included modernisation of equipment, mobile telephones, and automatic rerouting of out of hours calls.

At present the most popular transfer system for out of hours calls is the answering machine, used by 805 general practitioners $(60 \%)$. Recent technological advances that permit automatic transfer of calls between surgery and home are being adopted, and 342 respondents $(26 \%)$ reported they had them in their practice. Paging devices (bleeps) are widespread and 1133 respondents $(84 \%)$ said that they used them. Mobile telephones or radio links, often through ambulance control, were reportedly available to just 164 respondents $(12 \%)$.

\section{TELEPHONE CONTACTS BETWEEN PATIENTS AND DOCTORS}

Of the 1459 doctors who completed one of the questionnaires, only $37(3 \%)$ said that they were not prepared to accept daytime calls from patients, except in an emergency. Some $(285 ; 20 \%)$ reported that they routinely reserved fixed, regular times of day for handling patients' calls. The most common period for this was late morning: $80 \%$ of those who reserved time did so between 1030 am and $1230 \mathrm{pm}$, usually setting aside half an hour. Few allowed less than 15 minutes or more than one hour. Informal availability was high, both among those who reserved time and those who did not. Respondents to the full questionnaire completed a 
checklist of times in the day when they were prepared to accept non-emergency calls (table III). Again the period after morning surgery was most popular.

Willingness to accept patients' calls contrasted sharply with the estimated number of patient calls received in an average working day. Nearly $60 \%(848)$ of respondents to both versions of the questionnaire estimated that they received four calls or fewer. Doctors who reported that they reserved time received more calls on average than those who did not (table IV). In addition, doctors who were prepared to accept calls at most or all of the times listed in table III reportedly received significantly more calls than did those imposing greater restrictions on access times $(\mathrm{p}<0 \cdot 00001)$.

TABLE III-When general practitioners were prepared to accept patients' calls

\begin{tabular}{lc}
\hline & $\begin{array}{r}\text { No }(\%) \text { of doctors } \\
(\mathbf{n}=1270)^{\star}\end{array}$ \\
\hline Before morning surgery & $755(59)$ \\
After morning surgery & $1158(91)$ \\
Before evening surgery & $1024(81)$ \\
After evening surgery & $848(67)$ \\
During surgery: between patients & $861(68)$ \\
During surgery: with patients & $517(41)$ \\
Other times & $103(8)$ \\
\hline${ }^{\star}$ Excludes doctors who did not specify when calls were accepted.
\end{tabular}

${ }^{\star}$ Excludes doctors who did not specify when calls were accepted.

TABLE IV-Relation between estimated number of daytime patien calls and general practitioners reserving time for calls

\begin{tabular}{lccc}
\hline $\begin{array}{l}\text { Estimated } \\
\text { No of calls } \\
\text { a day }\end{array}$ & $\begin{array}{c}\text { No }(\%) \\
\text { reserving time } \\
(\mathbf{n}=266)\end{array}$ & $\begin{array}{c}\text { No }(\%) \\
\text { not reserving time } \\
(\mathrm{n}=1075)\end{array}$ & $\begin{array}{c}\text { All general } \\
\text { practitioners } \\
(\mathrm{n}=1340)\end{array}$ \\
\hline$\leqslant 2$ & $40(15)$ & $295(27)$ & $336(25)$ \\
$3-4$ & $90(34)$ & $368(34)$ & $458(34)$ \\
$5-6$ & $73(27)$ & $220(20)$ & $293(22)$ \\
$7-8$ & $29(11)$ & $89(8)$ & $118(9)$ \\
$\geqslant 9$ & $33(12)$ & $102(9)$ & $135(10)$ \\
\hline
\end{tabular}

$\chi^{2}=20 \cdot 95, \mathrm{df}=4 ; \mathrm{p}<0 \cdot 001$

${ }^{\star}$ Numbers in rows and columns may not correspond owing to computer weighting.

There was also a significant relation between the estimated number of patient calls received and the steps taken to inform patients that the doctor was accessible by telephone (table V). Nearly a quarter of general practitioners reported that they took no steps to inform patients. Over half relied on word of mouth alone, personally or through reception staff. The remainder made printed information available, usually in a practice leaflet, less commonly on a poster at the surgery, or rarely in a separate circular to patients. Those who took no steps received fewer calls on average than those who took any steps; those who provided printed material received more calls on average than those who relied on word of mouth alone.

TABLE $\mathrm{v}-$ Relation between number of patient calls and number of general practitioners reserving time for calls and steps taken to inform patients that they can call their doctor. ${ }^{\star}$ Values are numbers (percentages) of respondents

\begin{tabular}{|c|c|c|c|c|}
\hline & \multicolumn{3}{|c|}{ Steps taken to inform patients } & \multirow[b]{2}{*}{$\begin{array}{c}\text { All general } \\
\text { practitioners } \\
(\mathrm{n}=1258)\end{array}$} \\
\hline & $\begin{array}{c}\text { None } \\
(\mathrm{n}=295)\end{array}$ & $\begin{array}{l}\text { Word of mouth } \\
\text { only } \\
(n=676)\end{array}$ & $\begin{array}{l}\text { Word of mouth } \\
\text { and printed } \\
\text { material } \\
(\mathrm{n}=287)\end{array}$ & \\
\hline \multicolumn{5}{|l|}{ Estimated No of calls a day $\dagger$} \\
\hline$\leqslant 2$ & $97(33)$ & $149(22)$ & $40(14)$ & $286(23)$ \\
\hline 3-4 & $95(32)$ & $252(37)$ & $98(34)$ & $445(35)$ \\
\hline $5-6$ & $48(16)$ & $154(23)$ & $79(28)$ & $281(22)$ \\
\hline $7-8$ & $36(12)$ & $48(7)$ & $32(11)$ & $116(9)$ \\
\hline$\geqslant 9$ & $19(6)$ & $73(11)$ & $38(13)$ & $130(10)$ \\
\hline Time reserved for patients' calls $₫ \rrbracket$ & $5(2)$ & $143(56)$ & $104(41)$ & $252(100)$ \\
\hline No time reserved for patients' calls $\oint$ & $290(28)$ & $533(53)$ & $183(18)$ & $1006(100)$ \\
\hline
\end{tabular}

^Excludes general practitioners not prepared to accept non-emergency calls or not specifying steps taken to inform patients.

patients. $\chi^{2}=48.99, \mathrm{df}=8 ; \mathrm{p}<0.00001$.

$\neq \chi^{2} 111 \cdot 27, \mathrm{df}=2 ; \mathrm{p}<0 \cdot 00001$.

$\S$ Percentages are of total number of general practitioners giving that response.
Table $\mathrm{V}$ shows that general practitioners who reserved time were more likely to inform patients of their availability than were those who did not and were more likely to provide printed material.

Most respondents, including those who returned abbreviated questionnaires $(1312 ; 90 \%)$, also initiated personal calls to patients, though unsolicited comments indicated that this was a rare event. Overwhelmingly, such calls related to the results of tests, particularly results that demanded immediate action or when patient anxiety was a factor. Test results and the way in which they are transmitted formed a separate section of the questionnaire. It proved difficult to obtain general information. The type of test, the nature of the result, and the patient involved dictated whether results were given over the telephone, and many respondents were unwilling to commit themselves to a single usual course of action.

DIFFERENCE BETWEEN RURAL AND NON-RURAL GENERAL PRACTITIONERS

It was originally expected that general practitioners in rural and semirural areas would be more likely to reserve time for patients' calls than their urban and suburban counterparts and would also receive more calls from patients. For the most part this proved unfounded. The sample receiving rural practice payments were not significantly more likely to reserve time than the sample who did not receive payments $(23 \%$ rural practitioners $v 19 \%$ non-rural), nor did they receive significantly more patient calls $(21 \%$ v $19 \%$ received seven calls or more a day). Because rural practice payments are extremely complex and based, in part, on outdated area criteria, respondents were also asked whether their practice area was predominantly rural, semirural, suburban, urban, inner city, or other. Here there was a gradual increase in the proportion reserving time as the ruralness of the area increased; $28 \%$ of general practitioners based in predominantly rural areas reserved time compared with $15 \%$ of those describing their practices as inner city. There was also a slight increase in the estimated number of calls among general practitioners in rural areas. However, neither relation was significant.

\section{Discussion}

General practitioners in England and Wales reported an average of four telephone contacts with patients a day, compared with averages ranging from seven to 23 in American and Canadian studies. ${ }^{3}$ There was an apparent disparity between the low number of contacts and doctors' reported willingness and availability to accept patient calls. This may be due to several factors.

General practitioners may seem less accessible to patients than they believe themselves to be. For doctors who are reluctant to accept calls while conducting surgeries, even between patients, informal periods of availability while on the premises but not caring for patients may be quite short. Even those who reserve fixed times after morning surgery may not always be able to keep to them when surgeries overrun or emergencies intervene. Receptionists may shield doctors from some patient callers, " and many patients are probably unaware that their doctor is prepared to accept calls. ${ }^{17}$ A quarter of respondents said that they took no steps to inform patients that they would accept calls. Numbers of calls rose when patients were told by receptionists or doctors that they could telephone, but probably this is at best a selective method of informing specific patients about telephone access in certain circumstances. There was a further increase in the number of calls when written information on telephone access was reportedly made available. 
A further factor may be inadequacy of telephone lines, which would affect all telephone contacts with the surgery. It is impossible to judge whether an average of one incoming line per 3659 patients is adequate as this represents only supply and adequacy will also relate to demand. Possible demand factors include booking appointments, the ability to order repeat prescriptions by telephone, and the ability to speak to the doctor. Ratios are apparently unrelated to these factors. Larger practices, which generally had more lines than smaller practices, also had higher patient to line ratios. This may indicate that economies of scale are possible but may equally represent poorer telephone access for patients. Although larger practices in particular had exdirectory lines or lines reserved for outgoing calls only, the main benefits of this will presumably be for the practice rather than for the patients.

Though organisational factors such as size of practice and use of appointment systems should influence demand, so too will less obvious factors such as the flow of calls throughout the day. In some practices $40-50 \%$ of all appointment requests are made between 9 am and $11 \mathrm{am} .{ }^{18}$ Where practices are also channelling requests for home visits and repeat prescriptions to the same time period they may add to early morning congestion.

With respect to telephone answering, an organised rota of receptionists with numbers tailored to meet fluctuations throughout the day seems sensible, but rotas were used by less than a third of practices. Leaving it to any receptionist who is free may result in long delays in answering, as peak periods for telephone calls and counter work coincide. Delays in answering may also result from delegating one person to answer all calls on several lines. It is difficult to see what practices achieve by directing some types of calls to specific lines if they do not also assign different members of staff to answer them.

At a basic level there seems to be a need for detailed recommendations and guidelines on telephone needs and telephone organisation in general practice. As no such guidelines currently exist, however, it seems reasonable to suggest that practices with 5000 or more patients per line should look carefully at whether this provision is adequate. Family health services authorities could have a substantial role in setting standards and maintaining them.

Experience in other countries suggests that the telephone can be an effective tool in assessing patients' problems, managing patient care, and organising workload. Certainly patients say that they would welcome improved telephone access. Whether British general practitioners will wish to encourage it is a moot point. Further study of doctor-patient calls and patients' perceptions of and experiences with telephone access to surgeries and their doctors is needed.

1 Anonymous. The telephone in general practice [Editorial]. BMF 1978;ii: 1106. 2 Office of Population Censuses and Surveys. General Household Survey 1985. London: HMSO, 1987

3 Hallam L. You've got a lot to answer for, Mr Bell. A review of the use of the telephone in primary care. Fam Pract 1989;6:47-57.

4 Bhopal JS, Bhopal RS, Gilmour WH, Fallon CW. An audit of incoming telephone calls to a practice. Update $1988 ; 37: 848-51$.

5 Cubitt T, Tobias G. Out of hours calls in general practice: does the doctor's attitude alter patient demands? $B M 7$ 1983;287:28-30.

6 Crowe MGF, Hurwood DS, Taylor RW. Out of hours calls in a Leicestershire practice. $B M \mathcal{F} 1976$; i: 1582-4.

7 Hobday PJ. Telephone management of out of hours calls. 7 R Coll Gen Pract 1988;38:35-6.

8 Marsh GN, Horne RA, Channing DM. A study of telephone advice in managing out-of-hours calls. IR Coll Gen Pract 1987;37:301-4.

9 Russell T. Telephones and their systems. Practitioner 1976;197 (Suppl):3-10.

10 Watts CAH. The hot line. BMF 1971;3:419-21.

11 Arber $S$, Sawyer $L$. The role of the receptionist in general practice: a 'dragon behind the desk'? Soc Sci Med 1985;20:911-21.

12 Allen D, Leavey R, Marks B. Survey of patients' satisfaction with access to general practitioners. $\mathcal{J} R$ Coll Gen Pract 1988;38:163-5.

13 Anonymous. General practitioners set up morning phone-in for patients. General Practitioner 1986; Nov 28:1.

14 Anonymous. 'Phone in' for consultation. Pulse 1987;47(Sep 5):67.

15 British Medical Association. General practice: the facts. GMSC News Review 1989; Jan: V.

16 Department of Health and Social Security. Health and personal social services statistics for England, 1990. London: HMSO, 1990.

17 Allen D, Marks B. Patient access and appointment systems. Practitioner 1988;232:1380-2.

18 Leavey R. The organisation of practice resources and user satisfaction with accessibility. Manchester: Centre for Primary Care Research, University of Manchester, 1988.

(Accepted 14 February 199I)
During Clegg's editorship the fournal provided coverage of all the myriad changes occurring in medicine. As we have seen, the establishment of the NHS was of major concern in 1947 and 1948. Thereafter, the health service became a prime feature of the BMF's contents in any and every year. During periods of perceived crisis it could become a dominant preoccupation; in the first six months of 1957, for example, it was the subject of 19 leading articles. Other major developments in health and medicine were given the "Clegg treatment."

In his first summer as editor there occurred "the worst epidemic of poliomyelitis yet encountered in Great Britain." Thereafter, for more than a decade the disease took a grip on the popular imagination which far outstripped its importance in terms of morbidity and mortality. The alleged dangers of public swimming baths, flies, unwashed fruit and vegetables, and over exertion provided the basis for much tabloid sensationalism though, as a Fournal leader pointed out in 1950, the "risk of contracting poliomyelitis in its paralytic form is, even in a sharp epidemic, far less than it is popularly imagined to be." The fournal provided regular epidemiological reports on the disease, information on treatment, and exhaustive coverage of the vaccination debate. In 1956 the Ministry of Health announced its scheme for the mass vaccination of children born between 1947 and 1954, the operation of which turned the fournal into a trenchant critic of government policy. Leading articles headed, "Another ministry blunder," "Polio fantasies," and "Cheap propaganda on polio" show that the fournal could be as fierce a critic of a Conservative as of a Labour government. As well as renewing the fournal's emphasis on international affairs and scientific medicine, Clegg paid close attention to the broad social and political context of medicine, another aspect of the fournal which had waned during the 1920s and 1930s. Thus, in the 1950s and 1960s the Fournal concerned itself with the end of rationing, "Teddy" boys, glue sniffing, drugs in athletics, motorcycle crash helmets, food irradiation, drunken driving, space travel, the nuclear threat, child abuse, the Common Market (as it was then called), changing sexual morality, the ethics of human experimentation (a particular interest of Clegg's), family planning, toxic pesticides, boxing and brain damage, the televising of surgical operations, abortion law, and so on. One topic that merits closer examination is the series of papers by Doll and Bradford Hill on smoking and lung cancer, which made such an impact in the 1950s and early 1960 s. Their research, much of which was published in the $B M \mathcal{F}$, played a large part in establishing an incontrovertible link between tobacco smoking and lung cancer. In consequence, the fournal came to the forefront of the movement to publicise the dangers and reduce the incidence of smoking,

From Mirror of Medicine: A History of the BMf by P W J Bartrip. Published jointly by the $B M \mathcal{F}$ and Oxford University Press; BMA members' price UK $£ 29$, overseas $£ 33$, including postage. Obtainable from the Publishing Manager, $B M \mathcal{F}, \mathrm{PO}$ Box 295, London WC1H 9TE. Non-members UK £35. Obtainable from OUP Distribution Services, Saxon Way West, Corby, Northamptonshire NN18 9ES. 